\title{
Meeting the Needs of Students with Learning Disabilities in Inclusive Mathematics Classrooms: The Role of Schema-Based Instruction on Mathematical Problem-Solving
}

\section{Citation}

Jitendra, Asha K., and Jon R. Star. 2011. Meeting the needs of students with learning disabilities in inclusive mathematics classrooms: The role of the schema-based instruction on mathematical problem-solving. Theory Into Practice, 50, no. 1: 12-19.

\section{Published Version}

doi:10.1080/00405841.2011.534912

\section{Permanent link}

http://nrs.harvard.edu/urn-3:HUL.InstRepos:4889487

\section{Terms of Use}

This article was downloaded from Harvard University's DASH repository, and is made available under the terms and conditions applicable to Open Access Policy Articles, as set forth at http:// nrs.harvard.edu/urn-3:HUL.InstRepos:dash.current.terms-of-use\#OAP

\section{Share Your Story}

The Harvard community has made this article openly available.

Please share how this access benefits you. Submit a story.

\section{Accessibility}




\title{
Running Head: SCHEMA-BASED INSTRUCTION
}

Meeting the Needs of Students with Learning Disabilities in Inclusive Mathematics Classrooms:

The Role of Schema-Based Instruction on Mathematical Problem-Solving

\author{
Asha K. Jitendra \\ University of Minnesota
}

Jon R. Star

Harvard University

Acknowledgement. This article is based on research supported by the Institute of Education Sciences, U.S. Department of Education, through Grant \# R305K060075. The opinions expressed are those of the authors and do not represent views of the U.S. Department of Education. 


\begin{abstract}
In this article, we discuss schema-based instruction (SBI) as an alternative to traditional instruction for enhancing the mathematical problem solving performance of students with learning disabilities (LD). In our most recent research and developmental efforts, we designed SBI to meet the needs of middle school students with LD in inclusive mathematics classrooms by addressing the research literatures in special education, cognitive psychology, and mathematics education. This innovative instructional approach encourages students to look beyond surface features of word problems to grasp the underlying mathematical structure of ratio and proportion problems. In addition, SBI introduces students to multiple strategies for solving ratio and proportion problems and encourages the selection of appropriate strategies.
\end{abstract}


Meeting the Needs of Students with Learning Disabilities in Inclusive Mathematics Classrooms:

The Role of Schema-Based Instruction on Mathematical Problem-Solving

A significant number of students (about $6 \%$ to $7 \%$ ) in the U.S. demonstrate poor

achievement in mathematics (Swanson \& Olga, 2006). Although mathematics achievement has improved over the years, the achievement rates of students with disabilities in particular remain considerably lower than those for other students. This disparity suggests that more needs to be done to make school mathematics instruction accessible to all students. Further, educational equity is one of several principles articulated in the National Council of Teachers of Mathematics Standards (2000) and is based on the fundamental notion that all students, "regardless of personal characteristics, backgrounds, or physical challenges" (NCTM, 2000, p. 12) should have access to a curriculum that is challenging. The literature includes several studies of equity that have involved low-income, minority students (e.g., Fennema, Franke, Carpenter, \& Carey, 1993; Moses, 2001; Silver, Smith, \& Nelson, 1995), who have benefited from challenging (reformbased) mathematics programs. However, the beneficial effect of reform-based mathematics programs for students with learning disabilities is not well documented. Preliminary evidence suggests that these students do not respond adequately to core instruction in reform-based mathematics classrooms and require considerable accommodations to participate in small group activities and whole class discussions (e.g., Baxter, Woodward, \& Olson, 2001; Baxter, Woodward, Voorhies, \& Wong, 2002; Woodward \& Baxter, 1997).

Most notably, students with learning disabilities have difficulty with basic mathematical concepts and skills that negatively impact their ability to solve novel problems. Improving these students' problem solving skills has proved to be a significant challenge for several reasons. Students with learning disabilities typically have deficits in attention, memory, background 


\section{SCHEMA-BASED INSTRUCTION 4}

knowledge, vocabulary, language processes, strategy knowledge and use, visual-spatial processing, and self-regulation (Baker, Simmons, \& Kame'enui, 1995; Geary, 2003), which presumably have a deleterious effect on one or more domains (e.g., mathematics, reading). As such, it is critical that interventions are designed to address these deficits and scaffold student learning. A body of literature is available that indicates the importance of practices to improve student learning in mathematics that include (a) systematic, explicit instruction, (b) student thinkalouds, (c) visual representations, (d) peer assisted learning opportunities in which students focus on problem details, observe or are guided by models of proficient students' problem solving, and (e) formative assessments to provide feedback to teachers and students (Baker, Gersten, \& Lee, 2002; Kroesbergen \& Van Luit, 2003; National Mathematics Advisory Panel, 2008). Schemabased Instruction (SBI), an alternative to traditional instruction, integrates many of these features to improve mathematical problem-solving outcomes for learners with diverse needs, including students with learning disabilities (see Jitendra, 2007).

\section{Mathematical Problem Solving and Traditional Instruction}

Students struggling in mathematics lag behind their peers academically and continue to experience difficulties in mathematical problem solving regardless of motivation. One plausible reason is that problem solving is not well addressed in many mathematics textbooks. Most textbooks do not provide opportunities to discriminate among problems that require different solutions, because all problems presented on a page can be solved using the same procedure (e.g., multiplication). A second concern is the use of superficial cues such as key words [(e.g., in all suggests addition, left suggests subtraction, share suggest division (Lester, Garofalo, \& Kroll, 1989)] that "send a terribly wrong message about doing math" (Van de Walle, 2004, p. 152). The reliance on keywords to select an operation or a solution procedure (e.g., "cross multiply") can 
lead to systematic errors. For example, in the problem, "During a vacation to Rome with her family, Chaya took some photographs with her digital camera. When she returned home, she deleted 9 of the photographs. Now, she has 72 photographs left of her trip to Rome. How many photographs did she have in her camera initially?" students may focus on the keyword, left, and subtract even though the solution requires addition as the operation. As a result of applying the key word method, students struggling in mathematics have persistent difficulties in mathematical problem solving despite plenty of practice. The keyword method does not emphasize the meaning and structure of the problem and thus may not help students to reason and make sense of problem situations, which is crucial in solving novel problems (Ben-Zeev \& Star, 2001). Third, a general heuristic approach based on George Pólya's (1990) four-step problem solving model (i.e., understand the problem, devise a plan, carry out the plan, and look back and reflect) used commonly in mathematics textbooks is problematic for students struggling in mathematics. One concern is that general heuristics do not reliably lead to improvements in students' word problem solving performance (Lesh \& Zawojewski, 2007; Schoenfeld, 1992). The strategies in the "devise a plan" step are too general to support the learning of students struggling in mathematics. For example, a common strategy, "draw a diagram," may not necessarily generate a representation that depicts the relations between critical elements (e.g., part-to-part or part-to-whole comparisons) in the problem essential for successful problem solving (Hegarty \& Kozhevnikov, 1999). Further, the characterizations of strategies in the general method are "descriptive rather than prescriptive" (Schoenfeld, 1992, p. 353) and may not provide the necessary detail for individuals who are not already familiar with the strategies to implement them. 


\section{SCHEMA-BASED INSTRUCTION 6}

\section{Word Problem Solving and Schema-Based Instruction (SBI)}

Our instructional approach (SBI), which is intermediate in generality between key word and general heuristic methods, was designed to address the research literatures from multiple disciplines (special education, cognitive psychology, and mathematics education) to meet the diverse needs of students struggling in mathematics. Although SBI incorporates systematic and explicit instruction that special education promulgates for students with disabilities (Kroesbergen \& Van Luit, 2003), it draws largely from schema theory of cognitive psychology. As such, it addresses some of the concerns with traditional problem solving instruction primarily by going beyond surface features of word problems to identify the problem schema (semantic structure) and analyze underlying mathematical relationships that are critical to successful problem solving (Marshall, 1995). Change, Group, Compare, Restate, and Vary problems represent the set of schemata in the domain of arithmetic word problems (Marshall, 1995). These schemata are categorized into either additive or multiplicative structures. Change, Group, Compare problems belong to the additive field, because the solution operation is either addition or subtraction. In contrast, Restate (i.e., multiplicative compare) and Vary (i.e., equal groups, proportion) problems belong to the multiplicative field, because the solution operation is either multiplication or division (Christou \& Philippou, 1999).

Change problems involve situations in which "there is a permanent change over time in the value of one variable" (Kalyuga, 2006, p. 5). The Change schema usually begins with an initial quantity and a direct or implied action causes either an increase or decrease in that quantity. In the problem, A squirrel made a pile of nuts. It carried away 15 nuts up to its nest. Now there are 38 nuts in the pile. How many nuts were in the pile at the beginning? the unknown quantity (the initial number of nuts in the pile) was changed, and the resulting quantity is 


\section{SCHEMA-BASED INSTRUCTION 7}

specified. The Group schema involves a number of smaller groups combining to form a new larger group, with an emphasis on the part-part-whole relation. The Group problem, A new baseball bat costs $\$ 50$. A new baseball cap costs $\$ 10$. How much would it cost to buy the baseball bat and cap? requires understanding that the unknown quantity (cost of the baseball bat and cap) comprises two parts, baseball bat (\$50) and cap (\$10). The Compare schema involves a situation that compares two distinct, disjoint sets (compared and referent) and the relation between the two sets is emphasized. In the problem, At the park, there were 8 children on the slide and some children on the swings. There were 5 more children on the slide than on the swings. How many children were on the swings? the two things compared are the number of children on slides (8) and children on swings (the unknown quantity) and the relation between the two sets is a difference of 5 .

The Restate schema involves situations in which a relation exists between two things (e.g., twice as much as, $\mathrm{n}^{\text {th }}$ times) and there is a "restatement of this relationship using values different from those involved in the initial relation statement" (Kaluga, 2006, p. 6). This schema represents ratio-type situations such as the following problem: Orange juice concentrate is mixed with water in the ratio of 1:3. How many cans of orange juice need to be mixed with 6 cans of water? This problem type involves a known relation between two things $(1: 6$, or 6 times as much), and the same relation applies to two different values describing the same things: unknown amount of orange juice and 6 cans of water, which should be 6 times more than the amount of orange juice concentrate expressed in cans. So, 1:3 $=x: 6$, or 2 cans of orange juice is needed to mix 6 cans of water. In contrast, the Vary schema represents a situation in which "a systematic relationship exists between the amounts of two different things. If the amount of one thing varies (decreases or increases), the amount of the second thing changes in a fixed way. 
These situations could be redescribed as involving "IF ...THEN" relationship" (Kalyuga, 2006, p. 6). The Vary problem, Yuri can eat 3 hotdogs in 2 minutes. At this rate, how many hotdogs can he eat in 6 minutes? describes a relation between hotdogs eaten and the time taken. If the amount of time increases (three times, in this instance), then the number of hotdogs eaten will also increase by three times.

These schemata are hierarchically organized, cognitive structures that are acquired and stored in long-term memory. Because multiple elements of information are chunked into a single schema, a distinctive feature of schema-based knowledge structures held in long term memory is that when one piece of information is retrieved from memory during problem solving, other connected pieces of information will be activated. SBI also borrows from cognitive psychology the use of metacognitive strategy knowledge (e.g., self-monitoring) to facilitate reflecting on the problem solving processes for "comprehending problem statements, organizing information or data, planning solution attempts, executing plans, and checking results” (Coldberg \& Bush, 2003, p. 168). Further, flexible use of well-articulated problem solving strategies (e.g., unit rate, equivalent fractions) in SBI is based on the mathematics education literature that supports comparing and contrasting multiple solution methods (Rittle-Johnson \& Star, 2007; Star \& Rittle-Johnson, 2009). In light of working memory deficits evidenced by students with disabilities, SBI explicitly teaches a small but adequate number of strategies to scaffold student learning by providing explicit instruction.

Successful problem solving entails both problem representation (modeling the problem situation) and problem solution. Expert performance is characterized by the ability to translate and integrate information in the problem into a coherent mental representation that mediates problem solution (Mayer, 1999; Mayer \& Hegarty, 1996). For students with LD, teaching them 
to represent the situation described in the problem using schematic diagrams is critical to reduce working memory resources. As such, SBI focuses students' attention on the problem schema (e.g., Proportion) and helps them represent the relations between the different elements described in the text using schematic diagrams (e.g., Hegarty \& Kozhevnikov, 1999; Janvier, 1987; Willis \& Fuson, 1988). A schematic diagram depicts the spatial relations between objects in the problem text (Hegarty \& Kozhevnikov, 1999) and differs from pictorial representations of problems that include concrete, but irrelevant details, which "are superfluous to solution of the math problem" (Edens \& Potter, 2006, p. 186). Because the difficulty of the problem may be a function of the difficulty in understanding the problem situation, the nature of representations in our SBI model not only focus on the problem schema (e.g., Proportion) maintained in long-term memory, but also emphasize information (nonmathematical) contained in the situation model, as described by Van Dijk and Kintsch (1983). The situation model "is a temporary structure stored in working memory [and]... corresponds to a level of representation that specifies the agents, the actions, and the relationships between the events in everyday contexts" (Thevenot, Devidal, Barrouillet, \& Fayol, 2007, p. 44). Below is a description of how SBI, in conjunction with selfquestioning to monitor the learning process, can be used to help students solve word problems (e.g., Proportion).

\section{Teaching Problem Solving with SBI}

The SBI intervention described here is based on our work with middle school students with learning difficulties (Jitendra, Star, Starosta, Leh, Sood, Caskie et al., 2009). A four-step strategy (FOPS; F - Find the problem type, $\mathrm{O}$ - Organize the information in the problem using the diagram, P - Plan to solve the problem, S - Solve the problem) helps anchor students' learning of the problem solving process. The teacher uses a checklist based on the strategy steps 
to scaffold the cognitive processes as he/she thinks aloud to solve word problems (e.g., proportion). For example, consider the following problem: Toshi used exactly 2 cans of icing to cover 24 cupcakes. How many cupcakes can she ice with 3 cans of icing? Using Step 1 of the strategy, the teacher identifies the problem as a proportion problem by reading, retelling, and examining information in the problem to recognize it as a proportion problem via selfinstructions (e.g., Is there a If-Then statement of equality between two ratios? Does the If statement describes a rate/ratio between two quantities and the Then statement involves either an increase or decrease in the two quantities, but with the same ratio?). In addition, the teacher makes the connection between previously solved problems by noting that this problem is different from the ratio problems solved earlier, because this problem compares quantities with different units (e.g., cans of icing, cupcakes) rather than the same units (boys to girls or boys to students) as in the ratio problem. At the same time, the proportion problem is similar to ratio word problems in that they compare two ratios that are equivalent and require solving for the unknown quantity in one of the ratios.

For Step 2, the teacher demonstrates how to organize information using the schematic diagram (see Figure 1). This step includes self-instructions to read the problem to identify critical information in the problem to represent using the schematic diagram. For example, questions such as, "What does this problem compare? (Cans of icing and cupcakes) and "Does the problem describe a specific ratio between cans of icing and cupcakes? (Yes, both the statement and question in the problem describe the number of cans of icing and cupcakes.) are used to make sense of the problem situation. Specifically, the questioning makes public the two quantities (cans of icing and cupcakes) that form a ratio, which are first represented in the diagram followed by writing the quantities and units for each of the two ratios that are given and an " $x$ " 
for what must be solved in the diagram. The teacher then analyzes the problem situation using the completed diagram as follows: If 2 cans of icing cover 24 cupcakes, then 3 cans of icing will cover $x$ cupcakes (see Figure 1).

Step 3 involves translating the information in the diagram into a math equation. From the proportion diagram, the ratio presented in the "If" statement ( 2 cans of icing to 24 cupcakes or $\frac{2}{24}$ ) and the ratio presented in the "Then" statement ( 3 cans of icing to $x$ cupcakes, or $\frac{3}{x}$ ) are set up as follows:

$$
\downarrow \frac{2 \text { cans of icing }}{24 \text { cupcakes }}=\frac{3 \text { cans of icing }}{x \text { cupcakes }} \downarrow
$$

During this step, students learn to discriminate between instances when a particular solution strategy (e.g., cross-multiplication, equivalent fractions, unit rate) is appropriate based on the numbers in the problem. In this instance, students learn that the unit rate strategy would be the easiest to apply. This strategy is represented by vertical arrows, which show that one reasons up or down to analyze the relationship between the two quantities. To solve for $x$, the teacher explores by starting with the given ratio $\left(\frac{2}{24}\right)$ and reasoning from the top to the bottom in the given ratio $\frac{2}{24}$, because $x$ is in the denominator in the second ratio. The teacher models using self-instructions by asking, " 2 multiplied by what number equals 24 ?” The answer is 12 (since 2 times $12=24$ ), so you take this multiplier and use it on the other ratio. Since you multiplied 2 by 12 to get 24 , you multiply 3 by 12 to get $x$. So, $3 \cdot 12=36$. That is, 36 cupcakes can be iced by 3 cans of icing. Teacher questions such as, "Does anyone know what the 12 that we got as a multiplier means?" serve to emphasize that 12 is the unit rate of cupcakes per can of icing. 
Finally, Step 4 has the students solve the problem using the solution strategy identified in Step 3, justify the derived solutions using the schema features as anchors for explanations and elaborations, and check the accuracy of not only the computation but also the representation. The following provides an illustration of the mathematical reasoning to make sense of the answer: Let's see... if 2 cans of icing cover 24 cupcakes, then 3 cans of icing cover 36 cupcakes. This seems right, because 3 cans should cover more than 2 cans. So, the answer 36 cupcakes, which is more than 24 cupcakes seems right. I will also check the answer by taking the ratio in the Then situation $\left(\frac{2 \text { cans of icing }}{24 \text { cupcakes }}=\frac{3 \text { cans of icing }}{x \text { cupcakes }}\right)$ and seeing if the value of this ratio is equal to the ratio in the If situation $\left(\frac{2 \text { cans }}{24 \text { cupcakes }}\right)$. When I simplify both ratios, I get $\frac{1 \text { can }}{12 \text { cupcakes }}$ (notice the 12 again - 1 can of icing per 12 cupcakes, or $\frac{1}{12}$ can of icing for every cupcake), which tells me that they are equivalent.

In sum, SBI encourages student "think-alouds" to monitor and direct problem-solving behavior along the following dimensions: (a) problem comprehension (e.g., "Did I read and retell the problem to understand what is given and what must be solved?", "Why is this a proportion problem?”, "How is this problem similar to or different from ones I already solved?”), (b) problem representation (e.g., "What diagram can help me adequately represent information in the problem to show the relation between quantities?"), (c) planning (e.g., "How can I set up the math equation?", "What solution strategy can I use to solve this problem?"), and (d) problem solution (e.g., "Does the answer make sense?", "How can I verify the solution?”).

Several studies have shown the benefits of SBI for improving the problem solving performance of many different groups of students, including students with learning disabilities (LD), attention deficit hyperactivity disorder (ADHD), as well as English language learners and 
nondisabled students struggling in mathematics (e.g., Fuchs, Seethaler, Powell, Fuchs, Hamlett, Fletcher, 2008; Jitendra et al., 2009; Jitendra et al., 2007; Xin et al., 2005). For example, in a recent study we conducted with seventh-graders in a middle school, students received 10 days of instruction from their regular classroom mathematics teacher on ratio and proportion topics (e.g., ratios, rates, solving proportions, scale drawings) (see Jitendra et al., 2009). Instruction took place during the regularly scheduled mathematics class for 40 minutes daily, five days per week. Students in the control group received instruction from their teachers who followed normal instructional procedures as outlined in the district-adopted mathematics textbook; SBI students received instruction using our instructional materials that replaced regular instruction on ratios and proportions. Results suggested that students in the SBI group outperformed students in a control group on a problem-solving test both at posttest and on a delayed posttest administered four months later. In addition, we found a similar pattern of findings for students with disabilities (SBI: $n=10$; control: $n=5$ ) at posttest. Use of SBI had a large impact on students' ratio and proportion problem solving. The average percent improvement from pretest to posttest on the PS test was $24 \%$ for SBI students compared to only $2 \%$ improvement for the control students.

\section{Summary}

In sum, students with disabilities can successfully learn problem-solving skills when instruction is designed to promote understanding. Moving beyond conventional problem solving procedures to developing deep understanding of the mathematical problem structure and fostering flexible solution strategies helped SBI students improve their problem solving performance. The schematic diagrams in SBI may have provided a "level of concreteness and support to help understand key concepts" necessary for successful problem solving (Gersten, 2005, p. 203). Other factors contributing to these students' successful performance may be 
attributed to the emphasis in SBI on metacognitive strategy knowledge to monitor problemsolving processes as well as explicit and systematic instruction (e.g., consistent, logical, and complete explanations). As such, SBI represents a promising approach for teachers to meet the provisions of the No Child Left Behind Act with regard to closing the achievement gap for students with disabilities. 


\section{References}

Baker, S., Gersten, R., \& Lee, D. (2002). A synthesis of empirical research on teaching mathematics to low-achieving students. The Elementary School Journal, 103, 51-73.

Baker, S. K., Simmons, D. C., \& Kame'enui, E. J. (1995). Vocabulary acquisition: Synthesis of the research. (Tech. Rep. No. 13). Eugene: University of Oregon, National Center to Improve the Tools of Educators.

Baxter, J., Woodward, J., Voorhies, J., \& Wong, J. (2002). We talk about it, but do they get it? Learning Disabilities: Research \& Practice, 17, 173-185.

Baxter, J., \& Woodward, J., \& Olson, D. (2001). Effects of reform-based mathematics instruction in five third grade classrooms. Elementary School Journal, 101, 529-548.

Ben-Zeev, T., \& Star, J. R. (2001). Spurious correlations in mathematical thinking. Cognition and Instruction, 19, 253-275.

Christou, C., \& Philippou, G. (1999). Role of schemas in one-step word problems. Educational Research and Evaluation, 5, 269-289.

Coldberg, P., \& Bush, W. (2003). Using metacognitive skills to improve 3rd graders' math problem solving. Focus on Learning Problems in Mathematics, 5(10), 29-48.

Edens, K., \& Potter, E. (2006). How students "unpack" the structure of a word problem: Graphic representations and problem solving. School Science and Mathematics, 108, 184-196.

Fennema, E., Franke, M., Carpenter, T., \& Carey, D. (1993). Using children's mathematical knowledge in instruction. American Educational Research Journal, 30, 555-583.

Fuchs, L. S., Seethaler, P. M., Powell, S. R., Fuchs, D., Hamlett, C. L., \& Fletcher, J. M. (2008). Effects of preventative tutoring on the mathematical problem solving of third-grade students with math and reading difficulties. Exceptional Children, 74, 155-173. 
Geary, D. C. (2003). Learning disabilities and arithmetic: Problem-solving differences and cognitive deficits. In H. L. Swanson, K. R. Harris, \& S. Graham (Eds.), Handbook of learning disabilities (pp. 199-212). New York, NY: Guilford Press.

Gersten, R. (2005). Behind the scenes of an intervention research study. Learning Disabilities Research \& Practice, 20, 200-212.

Hegarty, M., \& Kozhevnikov, M. (1999). Types of visual-spatial representations and mathematical problem solving. Journal of Educational Psychology, 91, 684-689.

Janvier, C. (1987). Problems of representation in the teaching and learning of mathematics. Hillsdale, NJ: Erlbaum.

Jitendra, A. K. (2007). Solving math word problems: Teaching students with learning disabilities using schema-based instruction. Austin, TX: Pro-Ed.

Jitendra, A. K., Griffin, C., Haria, P., Leh, J., Adams, A., \& Kaduvetoor, A. (2007). A comparison of single and multiple strategy instruction on third grade students' mathematical problem solving. Journal of Educational Psychology, 99, 115-127.

Jitendra, A. K., Star, J., Starosta, K., Leh, J., Sood, S., Caskie, G., Hughes, C., \& Mack, T. (2009). Improving students' learning of ratio and proportion problem solving: The role of schema-based instruction. Contemporary Educational Psychology, 34(9), 250-264.

Kalyuga, S. (2006). Rapid cognitive assessment of learners' knowledge structures. Learning and Instruction, 16, 1-11.

Kroesbergen, E. H., \& Van Luit, J. E. H. (2003). Mathematics intervention for children with special educational needs. Remedial and Special Education, 24, 97-114.

Lesh, R., \& Zawojewski, J. (2007). Problem solving and modeling. In F. K. Lester, Jr. (Ed.), Second handbook of research on mathematics teaching and learning (pp. 763-804). 
National Council of Teachers of Mathematics, Charlotte, NC: Information Age Publishing.

Lester, F. K., Garofalo, J., \& Kroll, D. L. (1989). Self-confidence, interest, beliefs, and metacognition: Key influences on problem-solving behavior. In D. B. McLeaod \& V. M. Adams (Eds.), Affect and mathematical problem solving: A new perspective (pp. 75-88). New York: Springer-Verlag.

Marshall, S. P. (1995). Schemas in problem solving. New York: Cambridge University Press.

Mayer, R.E. (1999). The promise of educational psychology Vol. I: Learning in the content areas. Upper Saddle River, NJ: Merrill Prentice Hall.

Mayer, R.E. \& Hegarty, M. (1996). The process of understanding mathematics problems. In R. J. Sternberg \& T.Ben-Zeev (Eds.), The nature of mathematical thinking. Mahwah, NJ: Erlbaum.

Moses, R. (2001). Radical equations. Boston: Beacon Press.

National Council of Teachers of Mathematics. (2000). Principles and Standards for School Mathematics. Reston, VA: Author.

National Mathematics Advisory Panel. (2008). Foundations for Success: The Final Report of the National Mathematics Advisory Panel. Washington, DC.: U.S. Department of Education.

Pólya, G. (1990). How to solve it. London: Penguin. (Originally published in 1945)

Rittle-Johnson, B., \& Star, J. R. (2007). Does comparing solution methods facilitate conceptual and procedural knowledge? An experimental study on learning to solve equations. Journal of Educational Psychology, 99, 561-574. 
Schoenfeld, A. H. (1992). Learning to think mathematically: Problem solving, metacognition, and sense making in mathematics. In D. Grouws (Ed.), Handbook of research on mathematics teaching and learning (pp. 334-370). New York:McMillan.

Silver, E., Smith, M., \& Nelson, B. (1995). The QUASAR project: Equity concerns meet mathematics education reform in the middle school. In W. Secada, E. Fennema, \& L. Adajain (Eds.), New directions for equity in mathematics education (pp. 9-56). New York: Cambridge University Press.

Star, J. R., \& Rittle-Johnson, B. (2009). It pays to compare: An experimental study on computational estimation. Journal of Experimental Child Psychology, 102, 408-426.

Swanson, H. L., \& Olga, J. (2006). Math disabilities: A selective meta-analysis of the literature. Review of Educational Research, 76, 249-274.

Thevenot, C., Devidal, M., Barrouillet, P., \& Fayol, M. (2007). Why does placing the question before an arithmetic word problem improve performance? A situation model account. The Quarterly Journal of Experimental Psychology, 60, 43-56.

Van de Walle, J. A. (2004). Elementary and middle school mathematics: Teaching developmentally (5 ${ }^{\text {th }}$ Ed.). Boston: Pearson Education, Inc.

Van Dijk, T., \& Kintsch, W. (1983). Strategies of discourse comprehension. New York: Academic Press.

Willis, G. B., \& Fuson, K. C. (1988). Teaching children to use schematic drawings to solve addition and subtraction word problems. Journal of Educational Psychology, 80, 191-201.

Woodward, J., \& Baxter, J. (1997). The effects of an innovative approach to mathematics on academically low achieving students in mainstreamed settings. Exceptional Children, 63, $373-388$. 
Xin, Y. P., Jitendra, A. K., \& Deatline-Buchman, A. (2005). Effects of mathematical word problem solving instruction on students with learning problems. Journal of Special Education, 39, 181-192. 
SCHEMA-BASED INSTRUCTION 20

\section{Figure Caption}

Figure 1. Schematic diagram for Proportion problem. 


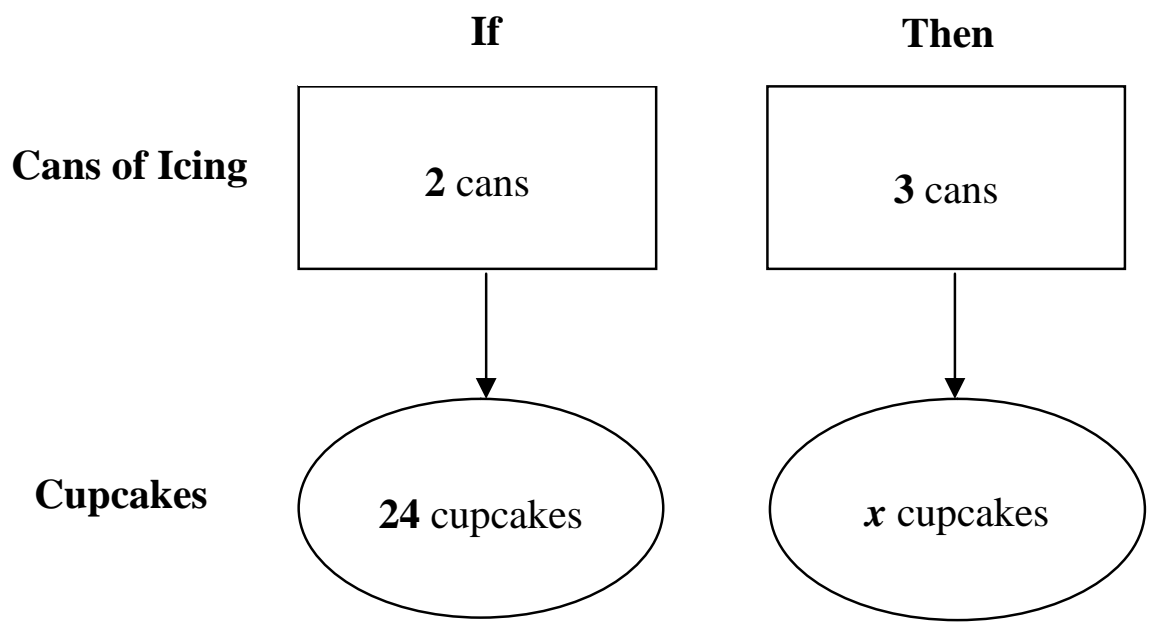

